\title{
SANTOS, PROMESAS Y EMBODIMENT. Experiencia y sentido de las ofrendas votivas en Galicia
}

\author{
Enrique COUCEIRO DOMÍNGUEZ \\ Universidad de La Coruña (España) \\ enriquec@udc.es
}

\begin{abstract}
SAINTS, PROMISES AND EMBODIMENT. Experience and meaning of votive offerings in Galicia
\end{abstract}

Resumen: Desde un enfoque que trata de conciliar las aproximaciones interpretativas y de la teoría del embodiment al estudio específico de los rituales religiosos, se trata el sentido y lógica de los tradicionales procesos de promesa y ofrenda votiva ejemplificados en los asociados a celebraciones gallegas en honor de santos abogosos. Asumiendo que la eficacia del ritual radica, en un aspecto esencial, en su extensión a lo orgánico, se propone que el proceso promesa-ofrenda votiva es experimentado como demostración, ritualmente pautada y desplegada, de la religación: de la vuelta a participar íntegramente el sujeto en todas y cada una de las dimensiones del universo existencial, como cuerpo vivo cuya sanación es públicamente constatada; como persona partícipe en la communitas humana; y como humilde interlocutor con la esfera sacra, al experimentar en carne propia lo que constata como beneficio derivado de la intervención divina.

Abstract: This work deals with the meaning and logic of the traditional processes of promise and votive offering, exemplified in those associated with Galician celebrations in honor of saints conceptualized as "abogosos" - that is, "singular mediators between the suffering offeror and the divinity'. In order to address that issue, I try to reconcile interpretative approaches and the theory of embodiment to the specific study of religious rituals. Assuming that, in an essential aspect, the effectiveness of the ritual lies in its extension to the organic, I propose that the promise-offering process is experienced as a demonstration, ritually guided and deployed, of the religation: of the subject's return to fully participate in each and every one of the dimensions of the existential universe. And to do it both as a living body whose healing is publicly verified; as a participant in the human communitas; and as a humble interlocutor with the sacred sphere, by experiencing in his own flesh what he sees as a benefit derived from divine.

Palabras clave: Ofrenda Votiva. Don. Santos. Religación. Encarnación Votive Offering. Gift. Saints. Religation. Embodiment 


\section{Introducción}

En una expresión que condensa magníficamente el fundamento de su teoría del embodiment (encarnación, corporeidad), Csordas (1990) afirma que "el cuerpo es el terreno existencial de la cultura". A partir esta idea basal, los avalistas de este enfoque se apartan de la clásica tendencia sociológica a retratar el cuerpo como un patrón pasivo para la organización social, o como un objeto estrictamente enclavado en el dominio de 'lo biológico' y desconectado de la mente. En cambio, conciben la experiencia corporal como algo previo a la conciencia. Al respecto, Merleau-Ponty (1962) perfiló la propuesta metodológica al alegar que, dado que la distinción sujeto-objeto es un producto del análisis, y los objetos en sí mismos son resultados finales de la percepción más que ser dados empíricamente a la percepción, es necesario un concepto que nos permita estudiar el proceso corporeizado de percepción desde el principio hasta el final, y no a la inversa: lo preobjetivo. La propuesta de Csordas sostiene esa constitución preobjetiva -y 'objetivante' a la postre- de la percepción, basándose en el viejo e influyente concepto de "técnicas del cuerpo" de Mauss, y en el de habitus, de Bourdieu (2012), quizá aún más influyente, aunque menos veterano. Con todo, el paradigma del embodiment no postula que la experiencia corporeizada sea previa a la cultura, sino que el partir de lo preobjetivo, de la percepción corporeizada, sugiere algo "pre-abstracto", no "pre-cultural", ofreciendo aquel concepto al análisis un proceso humano inconcluso de aceptación y habitación del mundo cultural.

Ese enfoque adopta una posición crítica respecto a los modelos hermenéutico y simbolista que orientan buena parte de la investigación antropológica (destacadamente, en antropología de la salud), en el sentido de que éstos han venido descuidando la importancia crítica del papel que las emociones, las vivencias físicas del cuerpo -el dolor, la fatiga, el malestar, aflicción y angustia personal e intransferible causados por la enfermedad; o en contraste, la salud, el alivio... - y dicha percepción individual desempeñan en la construcción y expresión de la experiencia, mientras que han volcado su atención en los procesos lingüísticos, discursivos, simbólicos y socio-estructurales que también concurren en la formación e información experienciales. Ante este metodológico desdén de la importancia de la corporalidad en la realidad vivida de la cultura, los teóricos del embodiment proponen (Jackson, 1983) que el cuerpo no es un inerte "convidado de piedra" del despliegue cultural en la incorporación personal de la experiencia, sino que las prácticas corporales pautadas engendran imágenes mentales e instilan cualidades morales. Es decir, que las prácticas corporales median una relación personal de los valores sociales. El paradigma del embodiment, en síntesis, al centrarse en el análisis que las prácticas del cuerpo desempeñan en los procesos de percepción y experiencia, se esfuerza por superar el hiato entre conocimiento y práctica, tratando de descentrar la construcción meramente cognitiva de la experiencia, y por abrir con ello terreno también a los factores emotivos y sensoriales. Este intento de ampliar el examen antropológico a todas las bases de la experiencia, reconociendo la centralidad protagonista del cuerpo socialmente contextualizado en la existencia y en la efectiva realización de 'lo cultural', resulta de interés de cara al estudio de las prácticas religiosas; y, dentro de ellas, las centradas en los procesos de ofrenda votiva a los santos.

No obstante, pese a la crítica adelantada por esta perspectiva 'somatocéntrica', sus patrocinadores no persiguen sustituir los abordajes sociológicos, interpretativos y simbolistas, sino completarlos, pues resultan ineludibles en cualquier análisis antropológico del cuerpo y sus usos como loci de ideación, comunicación y disputa de la realidad social y cultural. Así, remontándonos a una constatación de Mauss (1991), observamos que toda expresión corporal es adquirida por aprendizaje -por educación, o por mímesis no exenta de creatividad interpretativa-, de modo que el cuerpo deviene tanto el objeto original sobre el que la cultura efectúa su trabajo, como la herramienta original con la que se obtiene la cultura. De este 
modo dual, las "técnicas del cuerpo" puestas en práctica en contextos cotidianos y rituales, corresponden al cartografiado sociocultural del tiempo y el espacio. Es decir, el cuerpo es un objeto tan socioculturalmente modelado y condicionado como su puesta en escena (Lock, 1993). Y podemos seguir de ello, por implicación, que la experiencia del propio cuerpo y de sus tribulaciones, alivios y usos es posible por tal específico moldeado según patrones culturales, y en virtud de su activación en contextos sociales, que cualifican, dotan de valores y sentidos la percepción y la conciencia de las sensaciones corporalmente experimentadas.

Quizá, quien con mayor centralidad ha abordado el cuerpo desde la perspectiva simbolista es Mary Douglas (1978), al insistir en que los sistemas clasificatorios hacen uso de los 'símbolos naturales' -i.e., los límites internos y externos del cuerpo-, para reproducir y fijar en tiempo y espacio la estructura social, sus umbrales críticos y el orden moral dominante, mediante analogías de tipo metafórico y metonímico. Reafirmando también la primacía de lo cultural, Ellen (1977) subraya la importancia de la interacción entre lo cerebral, lo material y lo social, considerando que el impulso activo corresponde al condicionamiento sociocultural. Las perspectivas social y simbólica, en suma, reformulan el problema del cuerpo como una cuestión de semiosis social, combinada con algún reconocimiento del papel decisorio de la agencia individual. Con todo, quizá sea el enfoque adoptado por Rappaport (2003) el que más ha avanzado en la articulación de una perspectiva que conjugue lo somático y lo simbólico-social, como subrayaré tras un examen de la figura y dimensiones simbólicas de los "santos abogosos".

\section{Santos abogosos, promesas y ofrendas votivas. Ejemplos miñotas pontevedreses}

Ciertos santos son destacados como abogosos en Galicia, expresando la particular cualidad o virtud que la tradición atribuye a sus ambiguas instancias -de condición mistérica y modélica; humana y a la vez sobrehumana por sus virtudes- en tanto que distinguidos intercesores para la superación de crisis vitales, que a menudo tienen que ver con la enfermedad o los desórdenes y percances físicos. Las promesas a ellos formuladas, así como las entregas votivas en honor de sus figuras sacras, efectuadas en el seno de celebraciones periódicas y con las que se satisface el ciclo abierto con dichas promesas, conforman en articulación sintagmática un único proceso ritual-ceremonial. En tanto que rituales, las promesas y ofrendas presentan a la vez una faceta expresiva e instrumental. Atendiendo a la aproximación de Leach (2006) el ritual consiste en una declaración no verbal que comunica algo acerca de una situación o persona. Sin embargo, el papel del ritual no se agota en el acontecimiento expresivo, pues, como señala Turner (1980), los rituales fundamentalmente "hacen" cosas, de modo que mediante su performance se efectúan cambios en las personas y en las situaciones. El efecto del modo ritual de actuación tiende a ser integral: no sólo se actúa sobre los sentidos y la mente, sino también sobre las emociones y el cuerpo, al proveer, reorganizar, confirmar y encarnar nuevas visiones y sensaciones de la experiencia vivida.

Pueden distinguirse dos formas rituales: las de transición, que promueven cambios de estado y reorganización de las relaciones sociales; y las confirmatorias, que revivifican y revitalizan. No obstante, la realización de promesas y de ofrendas votivas a los santos confunde tal dualidad. Por una parte constituye un rito de tránsito, llevado a cabo para cambiar algún aspecto de la vida de un individuo, tal como sortear una crisis vital o librarse de una enfermedad. Pero el que las promesas culminen en el cumplimiento de lo prometido, en estricto ajuste de tiempo y forma al contexto cíclico del "día santo" o día propio de la festividad del santo abogoso cuya mediación fue impetrada, también las convierte en rituales de confirmación, porque en ese contexto celebrativo y ceremonial -y conforme a la articulación de procesos existenciales privados con órdenes públicos que, como veremos, señala Rappaport-, se despliegan, actualizan y demuestran las categorías fundamentales del cosmos, el orden social y la persona. Estos significados nucleares no sólo se revelan en el 
individuo, sino que se encarnan y reactivan en él: si atendemos al carácter modélico de los santos, sus días festivos son momentos especiales para insistir en actualizar ese plan emulando, aún a gran distancia, el dramático pathos de sus padecimientos, e interpretando en la sanación del propio cuerpo -o el del familiar- la acción interventora de la que el santo es afamado especialista.

Son innumerables las descripciones etnográficas de las promesas y ofrendas votivas en España, Grecia, Italia o Iberoamérica. Aquí mencionaré, como referencias para el posterior análisis, ciertos rasgos fundamentales de algunas de las ideas y prácticas ceremoniales tradicionalmente inscritas en el desarrollo de esos actos en la comarca bajomiñota pontevedresa, asociados a tres advocaciones de "santos abogosos" tomadas de entre las que resultan populares entre la población local. El rango devocional, la importancia y 'especialidad' advocativa de las tres celebraciones referidas son bastante disímiles, pero llamo la atención principalmente sobre ciertos modos de cumplimiento, recurrentes o singulares, que tienen en común una relación inequívoca con la corporalidad del oferente o de sus seres próximos.

\section{Santa Marta de Ribarteme. Vida/muerte}

La romería de Santa Marta de Ribarteme, celebrada el 29 de julio, constituye una de las convocatorias multisecularmente más concurridas y asentadas en el paisaje y calendario religioso de las gentes del Miño pontevedrés, junto a la de A Franqueira, la de Santa Tecla y la de San Campio. La formidable devoción a la Santa y multitudinaria asistencia a su romería en San Xosé de Ribarteme, (As Neves), responde a su notoriedad como "moi abogosa para os que están a morrer": es decir, como santa 'especializada' en interceder por aquellos que se encuentran en la definitiva encrucijada, prácticamente desahuciados por la enfermedad o por algún percance.

Tras la Misa Mayor del mediodía, seguida o contemplada por miles de concurrentes, entre fieles, curiosos, turistas y ofrecidos, sale de la iglesia la procesión encabezada por la imagen y el pondón de Santa Marta, más las tallas de San Benito y la Virgen del Carmen. Las suceden portadores de cirios - discreta forma de cumplimiento de promesa- y otros ofrecidos que avanzan penosamente de rodillas, auxiliados por algún familiar, con la peculiaridad de envolverse algunos de ellos con un pano o sudario de gasa blanca. Otros ofrecidos exponen su condición -y cumplen su promesa- avanzando de pie con sudario y vela encendida. Pero el culmen dramático se alcanza cuando se da paso a una hilera de personas empanadas (envueltas) en sudarios, portadas dentro de ataúdes descubiertos por cuatro o cinco familiares. El impactante patetismo de la escena es expresado así por un asistente:

“A procesión é unha cousa que pon medo de mirala... ¡Xúntase alí una chea de xente que mete medo! É unha emoción grandísima. Antes levaban a moitos metidos nas caixas, así, en fía... Alí é a procesión. Van cantando "Virgen Santa Marta / estrela do Norte/ Aquí te traimos / ó que estivo á morte". E "Virgen Santa Marta / estrela brillante / quen tivo a promesa / levamolo adiante".

La comitiva con féretros y oferentes empanados da varias vueltas en torno a la iglesia, mientras la grave intensidad de la escena es realzada al límite -ojos con lágrimas- por el repique de las campanas, el tempo solemne de la música de banda que acompaña, y la letanía referida. Al término, regresa la imagen al interior del templo, y allí los ofrecidos abandonan los ataúdes y unos y otros rezan ante la santa. Junto al carácter decididamente destacado de estos modos 'corporales' de cumplir as promesas, testimonios abrumadores de las tragedias personales y familiares sorteadas in extremis, se dan también otras formas habituales, aunque más discretas. Aparte de portar cirios encendidos, algunos oferentes depositan exvotos de cera en el interior del santuario, representativos de la totalidad del cuerpo o de la parte del 
mismo que, habiendo experimentado riesgo de pérdida o incapacitación, consideran salvada por intercesión de la Santa -brazos, piernas, cabezas o monecos que figuran la vida total del cuerpo-. En décadas pasadas también era llamativa la profusión de billetes de mil pesetas, colgados en el manto de la imagen, depositados en la hucha o por encima de sus andillas. Otra forma de cumplimiento -regular en otras muchas romerías devocionales- consiste en portar las varas de dichas andillas, pues se realizan puxas (sorteos) por el derecho a ello; y como suelen ser varios los ofrecidos cuya promesa consistiese en tal cometido, la competencia se intensifica, pudiéndose llegar a desembolsar pequeñas fortunas

En tiempos pasados, el cumplimiento de las promesas a Santa Marta podía alcanzar un cariz épico. Según un testimonio que recogí de un vecino de la distante Entienza (Salceda de Caselas), hace 33 años,

"P... da R..., que vive aquí, (...) levárono dentro dunha Caixa a Santa Marta... Foron veciños de aquí, que se ofreceron para eso. ¡E fixeron a pe todo o camino! ¿eh?, que queda ¡Buff! Moi lonxe de aquí. Iso foi... hai uns trinta ou carenta anos, pero moitos inda acordan porque foi sonado. [el ofrecido] Tiña que cumplir a promesa que fixo a sua familia cando o desahuciaron os médicos. Estaba a morrer por unha bronconeumonía que colleu. E o día propio, o da romería, sairon pola mañán, moi cedo, e estuveron andando a mañán enteira con a caixa ás costas pa chegar á procesión".

\section{Virxe do Libramento. Embarazo-parto}

La romería a la devoción de la Virxen do Libramento, celebrada de antiguo en San Esteban de Budiño (Salceda de Caselas) el 8 de septiembre, registra una multitudinaria concurrencia de romeros procedentes del Baixo Miño tudense, del Condado y del Val do Louro. De su vigor celebrativo da cuenta su gran poder de convocatoria, a pesar de la circunstancia de coincidir en fecha con A Franqueira, una de las grandes referencias de los cultos marianos gallegos. La Virxen do Libramento es una advocación de la Virgen María relacionada con el Adviento, la espera de la Natividad de Cristo; y en la interpretación popular de este perfil canónico, resulta reconocida como "abogada das mulleres en estado":

"fanlle promesas as mulleres en estado, para que o neno naza ben... é abogosa prós bós partos, e tamén prós nenos pequenos cando están malos".

En coherencia con esta identidad ligada a la encrucijada de la maternidad, la presencia femenina es mayoritaria en los actos litúrgicos de la mañana del día propio, a los que los romeros acuden tras juntarse en el turreiro de la iglesia. Resulta llamativo el contraste del bullicio festivo, donde menudean encuentros, charlas y consumo de rosquillas y "chiquitas de viño" en los postos, con la icónica, pero real, presencia de la muerte en los numerosos nichos sepulcrales que circundan el adro. Pero se contrapone aún más vivamente el tumultuario regocijo romero con el sufrido dramatismo de la procesión que sigue a la Misa Mayor, en la que las ofrecidas cumplen con el voto una vez elevado a la Santa. La romería se descubre así como un complejo celebrativo-ritual, a la vez unitario y plural, enfocado a conciliar opuestos, armonicen éstos o no: hay romería para mujeres y para hombres; para nenos y para vellos; para quienes se acercan a dar unha volta y chiquitear con compañeros, y para ofrecidos. Incluso para vivos y finados, convidados de piedra de lápida. El modo de participación de cada categoría de actor varía llamativamente, pero converge en cualquier caso en acción participativa. La comitiva procesional tras la Misa Mayor es encabezada por la cruz con los ciriales, seguida de altos pondóns que preceden la imagen de la Virxe do Libramento. En su manto cuelgan billetes prendidos con alfileres -algunas de las ofrendas 
votivas entregadas-. La segunda imagen procesional avanzando es la del Niño. Destaca, componiendo y flanqueando a la comitiva, la gran profusión de cirios encendidos portados por numerosas oferentes, y dotados de guías de madera que protegen de la cera fundida cirios cuya longitud equivale a veces, como disposición de la misma promesa, a la estatura corporal de la donadora o de aquella por quien se formuló la ofrenda-; mujeres o familias con niños en carritos... Pero el dramatismo callado del acto culmina en las personas de algunas ofrecidas -o de hijas o familiares más jóvenes de las mismas- arrastrándose de rodillas, eventualmente protegidas con almohadillas atadas:

"Ir de rodillas é un sufrimento moi grande... lastímanse moito, con feridas e sangue... ás veces deixan manchas de sangue polo camino... por eso os curas querían prohibirlo. Agora a xente que vai ofrecida ten a costume de levar uns trapos ou unhas almohadillas atadas para non lastimar as rodillas, inda que segue a ser moi fastidiado".

"Hai mulleres que se teñen ofrecido elas para ter un parto bó, ou para o parto de unha filla... E ó mellor logo, por edade ou porque non pode o corpo, cando teñen que cumplir a promesa, ó mellor é a irmá, ou otra filla, ou a nora a que cumple por ela, porque claro... Unha cosa é prometer o que se promete nun momento en que as cousas veñen mal e que... toleas, e outra poder cumplir o prometido".

No todas las formas de ofrenda responden al carácter dramático de la antedicha: en A Virxe do Libramento de Budiño -y en San Bartolomé da Lamosa, en Covelo- tiene su escenario una práctica singular:

"Unha costume é que as embarazadas leven unha cinta de tela bendecida ó redor da tripa, como un ofrecemento para que o parto veña ben, e sexa corto. Logo, ó ano, xa veñen as nais outra vez á festa cós nenos nacidos... de poucos meses".

La costumbre por un lado incorpora la iconografía del embarazo mariano, y por otra se resuelve en la exposición pública de los hijos al año siguiente, cuyo feliz nacimiento se atribuye a la intervención sacra: de nuevo el embodiment, la ofrenda corporalmente materializada, bien en la persona de los hijos -como ofrecidos-testimonios-, bien en ese elemento de continuidad metonímica que es la cinta que contorna el vientre fecundado y que, esta vez parece actuar como elemento propiciatorio, si no de consagración profiláctica, del curso ordenado de la reproducción humana y social en el momento quizá más crucial y comprometido de la vida -el que le da paso-.

\section{San Bartolomé. Crecimiento}

San Bartolomé es venerado en la comarca tudense, como abogoso supresor de los temores nocturnos infantiles, y como mediador para solucionar los tatalexos (tartamudeos) de los niños, o los problemas iniciales del habla. Las ofrendas votivas que se le brindan han consistido tradicionalmente en polos negros que se subastan el día propio de su romería al monte Alba. Por ellos pujan los oferentes sumas de dinero, y después los entregan en cumplimiento de sus promesas. De todos modos, la tradición dispone que para que el niño pequeño se libre de temores también sea preciso realizar el rito de pasarlo por debajo de la peana de la imagen, con ocasión del día propio de la romería, y facer petar tres veces la cabeza del infante bajo la base. Aunque esta acción no constituya en sí el cumplimiento de una 
promesa, sino un ritual que responde a una lógica propiciatoria, de nuevo, reiteradamente, se involucra al interesado en una ceremonia que experimenta y comunica corporalmente de forma integral, tanto en su propia vivencia como en el simbolismo de su ejecución; una ceremonia que tanto opera figurando simbólicamente un impulso al pleno nacimiento (un nuevo 'parto') a la normalidad social comunicativa, como indicando la plena sumisión de la persona a la instancia referente de la sacralidad:

"Dicen que si tú quieres quitarte el miedo, tienes que pasar por debajo de San Bartolomé, de la imagen... Yo, cuando era pequeño, pasé por debajo de la imagen... Lleváronme mis padres, porque decían que así perdería el miedo. Tienes que pasar por debajo de donde está el Santo, y petar tres veces... tres golpes con la cabeza en la madera de la base, por debajo. Te pones así, casi a rastras, e petas".

En esta advocación concreta, de todos modos, la forma específica de cumplimiento de promesa ofrece la particularidad de realizar la ofrenda no encarnándola en la propia persona, sino delegándola en el cuerpo de un animal, el pollo negro:

"Eu ofrecinlle un polo negro a San Bartolomé para que o meu fillo empezara falar, cando era pequeño, porque non daba falado... tardaba moito en soltarse a falar... Ofrécenlle pitos negros... A iglesia está chea de pitos negros que trae a xente... E tamén ofrécenlle pitos cando o neno tatexa ó falar, para que fale ben".

Pasando ahora a analizar el perfil específico de su posición simbólica, cabe señalar que, más allá de que los santos constituyan modelos para la imitación humana, la devoción efectiva conlleva la invocación de su ayuda, siendo tenidos como mediadores con Cristo para los fieles. Como correspondencia a la ayuda recibida, asociada al ruego impetrado, los beneficiados deben expresar su gratitud hacia el santo y el reconocimiento público de su excelencia sobrenatural -siendo, a propósito, que el proceso de la promesa nunca constituye una modalidad especial del utilitario do ut des-. El honrar a los santos puede conllevar su veneración en sus imágenes; no sólo las tallas, sino los actos ceremoniales que las incluyen erigiéndolas en símbolos dominantes, como el portarlas sobre las angarillas -lo cual a menudo constituye por sí mismo una forma de materializar como costoso cumplimiento una promesa realizada-. Dicho esto, puede llamar la atención que invariablemente se recurra a santos o a la Virgen, y no a la máxima instancia, como mediadores místicos ante los que uno se instituye voluntariamente en ofrecido. Si el fiel puede implorar a Dios solicitando el perdón, sin embargo no puede ofrecerle nada, dada su omnipotencia y la tremenda asimetría de la relación -dadas sus alteridades recíprocamente absolutas; el hiato y no la inmanencia con que tradicionalmente se contempla la relación entre lo sobrenatural y lo natural-. Pero una persona sí puede dirigirse directamente a un santo, ofrecerle un acto devocional y requerirle ayuda efectiva, implicando tácitamente la convicción de que el santo podrá, de su parte, interceder ante Dios o no hacerlo.

Esta figura de mediador y auxiliar para librarse de la enfermedad o de peligros de muerte asociados a las crisis vitales (partos, servicios militares, cirugías y demás) representa la principal función del santo; y la reciprocación del agradecimiento viene dada por la ejecución de las ofrendas votivas. Pero los santos, en tanto que poderosos símbolos de condensación, son empleados para estructurar y organizar la experiencia con consecuencias más allá de esta mediación personal, pues con respecto a ellos asimismo se jalona y erige uno de los ejes del tiempo culturizado, el calendario ritual anual. Los santos son destinados, entonces, a clasificar el mundo, y puesto que ordenar supone otorgar significado, las celebraciones en 
su honor que singularizan los días santos contribuyen a una recreación del orden y sentido del cosmos existencial. Desde esta lógica encuentra su coherencia el expreso mandato consuetudinario de que las promesas personales deban cumplirse "o día propio do santo", aquél en que se celebra su festividad con ceremonial efectividad.

Desde una óptica externa puede resultar llamativa la mixtura en tales contextos festivos del dramatismo patético de los ofrecidos, física y mentalmente consagrados a ejecutar con dura, muda y sufrida gravedad sus ofrendas votivas; con la prodigalidad en bebida, churrascos, música, colores, atuendos, pirotecnia y locuacidad (Gudeman, 1976). Pero tal contraste en realidad no supone un contrasentido global. Antes al contrario: magnifica el sentido de singularidad del propio contexto, desde todos los puntos cardinales de la experiencia vivida, apelando a una percepción corporal integral, inusitada, emotiva y multisensorial, mucho más que a cualquier comunicación racional limitadamente dirigida al raciocinio ordinario. El asalto a los sentidos cometido por el aparato festivo de sabores, sonidos, espectáculos, dramatizaciones u olores provoca la ruptura del filtro externo y ordinario que rodea a cada persona, de modo que pueda participar activamente en una experiencia extra-ordinaria, en un panóptico de la existencia propia y ajena. De nuevo podemos entender la participación festiva ligada a las figuras de los santos -y dentro de ella, particularmente, la consagrada a los cumplimientos de promesas votivas-, como revulsivo para la intensificación de la experiencia vivida y la consecuente transformación de la conciencia, en el sentido al que aludí anteriormente, apoyándome en Morinis (1985). Se trata de la vivencia de la communitas sin límites (Turner, 1988), de la excepcionalidad existencial públicamente refrendada y participada: aquella que precisamente abre el umbral, patrocinado por la figura del santo, donde puede culminar ritualmente, y tener cumplida cabida, todo privado proceso de ofrenda votiva.

Y es que el santo, y el sistema de santos, se encuentran en el borde mismo de la estructura (Gudeman, 1976): en un primer sentido, su idea proporciona nexos entre los símbolos públicos y los significados privados; y entre estos y la propia aflicción padecida. Actúan a modo de "símbolos transaccionales" adaptados ad hoc desde el mito general (Dow, 1986). Esos símbolos transaccionales se definirían como símbolos particularizados desde medios simbólicos generales, para su uso tanto en la diagnosis y la curación como, en general, en la conciliación personal con las condiciones de una existencia socialmente vivida. El individuo puede recurrir a este retablo integral de ideas y relatos colectivos, manejarlos y utilizarlos precariamente -aún sólo en algunos retazos de su inmensa red semántica-, para hacer comprensibles sus propias experiencias ordinarias y corporalmente inmediatas, angustiosas, urgentes $-\mathrm{O}$, simplemente, hacerlas asumibles en un sentido lato-. Pero también los santos cabalgan el limen estructural en un segundo sentido: el imaginario que conforman establece un equilibrio entre el pasado, figurado como una serie de acontecimientos significativos a la luz de los relatos hagiográficos -y también en virtud de recuerdos de fiestas y promesas vividas antaño-, y un presente y un futuro que podrán ser comprensibles si se ajustan al modelo de tales sucesos legendarios. En este sentido, sugiero que los santos actúan como marcados referentes de la mitopráxis aldeana tradicional (Sahlins, 1988): de esos relatos míticos, solemnes y sagrados con los que se sale al paso de los acontecimientos, afanes e incertidumbres que trae el devenir personal y colectivo, para domeñarlos -culturizarlos- y hacerlos descifrables, asumibles, dotándolos de porqué y de cómo. Al respecto, se evidencia que las estructuras mítico-narrativas en general, y las referentes a los santos en particular, influyen en el desarrollo, percepción y conciliación de los acontecimientos sobrevenidos que conforman la historia tanto comunitaria como personal (González, 2013). Aunque también, recíprocamente, la historia influya en la organización y transformación de las estructuras míticas.

En este punto conviene redirigir la atención desde la figura y simbolismo de los santos al campo constituido por los rituales de ofrenda votiva que los adoptan como ejes sim- 
bólicos dominantes. Avanzando más resueltamente que otros teóricos del simbolismo en antropología hacia un encuentro del análisis de la conducta simbólica con la perspectiva del embodiment, Rappaport (2003) apunta que la eficacia del ritual estriba, más allá de sus propiedades convencionales, en su extensión a lo orgánico; y así, la experiencia somática que brinda provoca la articulación de procesos psicosociales privados con órdenes públicos. Esta observación presenta un interés particular para nuestro examen del fenómeno de las ofrendas. Y no sólo por cuanto éstas conlleven recurrentemente formas de promesa y cumplimiento que involucran el sufrimiento, el esfuerzo o el auto-ofrecimiento corporal del oferente -o del familiar a quien éste encomiende o delegue tal ejecución-; o porque aquellas se 'pongan en acto' al tomarlas como recursos religioso-rituales eficaces para la superación de trances tan críticos y dramáticos como la enfermedad o el riesgo vital; ni aun meramente porque, aun cuando no impliquen una entrega directa del propio cuerpo -en forma de esfuerzo, sacrificio físico o exhibición ceremonial (i.e., la procesión de ataúdes en Santa Marta de Ribarteme)-, se acostumbre a verificarlas como entregas de exvotos inequívocamente "somatomórficos", sustitutivos del cuerpo del ofrecido, de la parte o miembro de éste (cabezas, piernas, brazos, pechos, etc.) por cuya sanación se impetra la intervención divina, o como prendas que están en contacto con la anatomía del oferente o aluden a la condición física que se trata de conducir o reconducir a buen puerto (i.e., la cinta ofrecida a la Virxe do Libramento). El efecto que provoca la extensión del ritual participado a lo orgánico -la experiencia encarnada- es la transformación o 'intensificación' de la propia conciencia ${ }^{1}$, resultante del proceso - del ritual de paso- que se extiende desde la elevación privada de la promesa a una instancia divina, pasando por la sanación, hasta el cumplimiento-manifestación pública de la ofrenda. Esta 'serie diacrónica de acontecimientos' pasa a percibirse y comprenderse, en virtud de su propia ritualización y del 'esquema cultural' que la informa, como un 'proceso causal de consecuencias', por el que el segundo paso (la curación a veces inmediata, la superación de una crisis personal) se interpreta como efecto demostrativo de la atención que la divinidad ha prestado al primero (el ruego que motiva la formulación de la promesa); y a su vez como motivo compulsivo del tercero (ejecución del cumplimento por el oferente, ajustada estrictamente a los términos en que fuera formulada la promesa). El cumplimento es realización consciente y expresamente apremiante, que supone la culminación de dicho proceso, por constituir la articulación inclusiva, por vía simbólico-ritual y corporal, del caso particular, de la identidad del propio yo oferente, en una experiencia a la vez íntima y colectiva, dirigida en un sentido único y compartido hacia la fusión en un mismo orden natural, social, sacro y existencial.

\section{Las ofrendas votivas y su lógica religatoria. Promesas frente a transacciones donaticias}

Para interpretar el proceso ritual de las promesas y ofrendas votivas dirigidas a estos sagrados "símbolos transaccionales" que son los santos abogosos, conviene mencionar una fórmula con la que clásicamente se ha pretendido explicar antropológicamente el fenómeno, junto al del sacrificio: hacerlo a la luz de la teoría maussiana del intercambio del don. Esta fórmula otorga el carácter de dones a las ofrendas y sacrificios en un intento de dilucidar sus significados. Pero los resultados por lo general han sido pobres, como ocurre al interpretar las ofrendas a modo de instrumentos para una astuta estrategia de "do ut des" con deidades y ancestros lo suficientemente hastiados como para dejarse engañar con la presentación de fruslerías (Van Baal, 1976). Así, previamente a Mauss, en la teoría de Tylor (1871) sobre el sacrificio, este aparece como un juego de 'doy para que des' más próximo a una estrategia de soborno que a una de adoración: soborno que se ofrecería para inducir a las deidades a

1 En un sentido próximo al que defiende Morinis (1985), para quien la transformación de la conciencia resulta de la "intensificación de la experiencia vivida", aunque este autor aluda a dicha transformación en referencia expresa al papel del dolor en los procesos de iniciación ritual. 
desviar su hierática atención a la satisfacción de los anhelos del suplicante. Para ello, claro está, la oferta debe ser sustancial, a riesgo de convertirse el oferente en un embaucador. Pero -siguiendo a Van Baal- esta teoría del don y el sacrificio se erigió sobre el modelo, sin más, de la humana corrupción; y fue rechazada dada su incompatibilidad con el significado de lo que es el imaginario y la experiencia de la religión.

A su vez, Mauss presenta el don como elemento instituyente de la obligación de dar, recibir y devolver, no siendo éstos los actos libres y voluntarios que parecen ser. Pero ello plantea otro problema: la reciprocidad no resulta nunca mecánica en la práctica, estando profundamente afectada por las contingencias del contexto, y también por las diferencias de status entre los actores del intercambio: la persona de menor status ha de devolver un bien menor, a riesgo de ser considerado un presuntuoso manirroto y retador (Van Baal, 1976). Siguiendo esta lógica, en el caso de las ofrendas religiosas, dada la abismal alteridad sacro/ profana entre oferente y deidad, el primero refrenda su radical minoría de estatus existencial con presentes que, si ponen de manifiesto un valor intrínseco, su entidad resulta incomparablemente menor a la del favor que espera recibir. Como argumenta Van Baal, la reciprocidad resulta un principio de probada importancia universal, ubicuamente reconocido y puesto en práctica en la interacción social. Su principal diferencia frente a la otra gran forma de intercambio de bienes, el comercio, consiste en que en el intercambio de dones los participantes apuntan a la otra persona en sí, mientras que en el comercio se concentran y detienen en los bienes del otro. El don comporta un mensaje de reconocimiento del otro como socio y amigo: como alguien que participa del 'nosotros'. Y transmite ese mensaje no con meras palabras, sino con la sólida y demostrativa facticidad de su presencia material, que reduciría el riesgo de ese engaño inherente a los mensajes simplemente lingüísticos, del que ya previno Rappaport $(2003)^{2}$. Por ello, el don -el don entre seres humanos, pero especialmente el intercambio de dones con la divinidad- constituye una respuesta al problema fundamental de la condición humana, la incertidumbre del hombre sobre sí mismo como miembro o parte del universo; universo de cuya objetiva continuidad, sin embargo, difiere en tanto que sujeto $\mathrm{y}$, por ello, en tanto que alguien permanentemente separado de su totalidad. El intercambio de dones puede representar un movimiento orientado hacia la superación de ese contrasentido de la permanente disociación de una totalidad en la que no obstante se participa -hacia la religación, en una palabra-. Es un movimiento que parece ir en la línea de satisfacer la urgente necesidad de comunicación en la que se instituye tal religación que otorga sentido conectivo a la vida; comunicación que no puede consistir en un mero intercambio verbal y cognitivo, sino que involucra, más allá, la inmersión en toda esa constelación de sentimientos y sensaciones corporales característica de la participación ritual, y que provoca-transmite esa conciencia vívida y reconfortante de la realidad de participar en el propio universo. Pues bien, si el don se dirige a la otra persona término de relación, deben ser tomados muy en cuenta su estatus y las circunstancias en las que se produce ese movimiento.

En este punto, es posible discernir con precisión los matices que diferencian profundamente la transacción de regalos entre humanos y la ofrenda votiva a la divinidad, por más que ambos casos se sigan inspirando fundamentalmente en el schema del don. Aunque la correspondencia a un don entregado entre humanos puede esperarse que se postergue sine die, no obstante se contempla tácitamente y da por entendida su obligación moral por el mero hecho palmario-material de la recepción-aceptación inicial de la entrega, no mediando un ruego explícito a la activación de la reciprocidad por parte del primer receptor. Ello es así siempre que no influya una gran diferencia de status, y no se plantee una situación crítica y urgente de gran necesidad por parte de quien trata de entregar el don: pero en estos últimos

\footnotetext{
2 Por más que no elimine del todo la posibilidad de engaño o la calculada ambivalencia, ya que a veces también la reciprocidad puede contener latentemente un elemento de confusión y ambigüedad, cuando es empleada como arma en reserva contra las personas que frustran las expectativas.
} 
casos el carácter donaticio de la maniobra queda eclipsado y casi privado de significación ante la expresa súplica verbal del peticionario, quien apelando al papel benefactor o mediador de la persona solicitada hace así manifiesta su disposición a quedar ligado con ésta en una relación desequilibrada de débito.

Pero ¿qué sucede cuando un hombre ofrece algo ante un ser distante según una alteridad absolutamente asimétrica, y en un contexto intensamente crucial, ligado a una seria crisis vital? Ante el Todopoderoso, las personas divinas y el misterio tremendo de su alteridad, se impone una exigencia categórica de humildad, de palabra y de hechos. El don muta en ofrenda; y a menudo en esa ofrenda lo más radical posible desde la propia y sumisa contingencia del ser mortal, que consiste en ofrendarse uno mismo en una integridad personal materializada en la corporalización: en el entregar el propio cuerpo, aunque sea en efigie, en representación icónica vicaria del trance superado o del miembro sanado, o a través del sufrimiento físico evidencia de la autoentrega. Pero lo significativo es que, ante lo sagrado, esa ofrenda ha de venir acompañada de la formulación del voto; de la impetración ritual de la súplica expresa, algo opuesto al carácter tácito de la entrega secular de regalos entre personas. Pedir -en contexto ritual- es un acto verbal que comunica el anhelo de vinculación desde la humillación más rendida: el reconocimiento incondicional e inmediato de la dependencia del solicitante y del poder del destinatario, de quien ni siquiera cabe constatar si se configura o no en receptor de la ofrenda. Es decir, lo que en contexto 'humano' no se puede hacer cuando se ofrece algo, solicitar expresamente un retorno, se debe hacer ante Dios o sus santos mediadores, pues proceder de modo contrario, ofrecer un 'obsequio' calladamente interesado, sería irreverentemente presuntuoso, si no equivalente a una suerte de profanación, al confundir simbólico-ritualmente límites entre lo sacro y lo profano y al tratar de equiparar lo que son inconmensurables magnitudes existenciales: al impugnar, en la falta de humildad que demuestra el no rebajarse a suplicar, la radical otreidad existente entre los términos de la relación ensayada. Por ello las ofrendas votivas se alejan, en sentido esencial, de la condición del don, ya que en ellas cobra más urgente y dramática significación la petición que lo ofrecido. No es que la transacción desaparezca, pues el schema sigue siendo el del don, y ante lo que se interpreta como una intervención sagrada en la curación o en que el hijo encuentre trabajo, como consecuencia de una promesa realizada, el "cumplir o prometido" es asunto expreso de obligación categórica. Pero lo ofrecido en sí queda supeditado desde el punto de vista simbólico a la deprecación, a la súplica. Una súplica que, significativamente -y según un informante de edad me describió-, es fórmula que debe solemnizarse en el curso de la Consagración, el más sagrado de los momentos litúrgicos; invistiéndose así del carácter de pacto trascendente, por intencional asociación indexical con la misma:

\footnotetext{
“A promesa, para facerla, hai que facerla no momento da Consagración: entre o momento en que o cura levanta a Forma, e o momento en que levanta a copa do viño... É entón cando un ten que prometer desde o máis dentro de un... a promesa".
}

Sea o no la aludida una pauta regular, interpreto en cualquier caso que esta peculiaridad de la promesa votiva se debe a que el conjunto del proceso apunta a la totalidad de la persona que lo inicia impetrando la santa abogacía; a su responsabilidad plena y trascendente, que le afecta por entero, y no al objeto material prometido. Es más, éste queda comúnmente eclipsado por -o identificado en- la misma persona física del oferente como tal, pues es esta la que se ha ofrecido a sí misma como objeto de cumplimiento de valor humanamente insuperable: de ahí la literalidad de la expresión popular ir ofrecidos; de ahí la coherencia de esta expresión con el hecho de que las principales formas de cumplimiento aludan inequívoca y a veces inmediatamente al cuerpo o a las partes corporales del oferente -al 'oferente en su 
integridad existencial' - y que en todo caso lo señalen como tal al exponerse públicamente (es decir, al demostrarse ritualmente), como votante activo, y en el público y debido contexto litúrgico o pre-litúrgico en que culmina el día santo. La confluencia de corporalización y humillación se hace diáfanamente expresa en los modos frecuentemente fatigosos, cuando no dolorosos, de realización de la promesa: en numerosos escenarios culturales, como advierte Glucklich (1999), el dolor llega a ser una experiencia significativa, más que un problema que se deba resistir y rechazar. Pero ¿por qué el dolor, o -más ampliamente- el sufrimiento tienden a tornarse especialmente significativos? Kleinman (1997:326) aporta una mirada particularmente lúcida: la otredad profunda del sufrimiento solo puede concebirse en la medida en que uno entiende que "su experiencia está dentro y fuera del límite del yo corporal, cruzando hacia adelante y hacia atrás como si ese cuerpo fuera permeable". Al respecto, sitúa la importancia de la creación de significado en su carácter de puente entre las representaciones culturales y los procesos transpersonales, por un lado, y los procesos corporales y la subjetividad por otro.

Para concluir, retomo el análisis de la especificidad del voto como transacción. El hecho de que el proceso de la ofrenda votiva de carácter religioso supone una forma excepcional de desarrollo del schema del don, aunque difiera del don entendido como contrato tácito entre humanos ${ }^{3}$, se muestra también en otro respecto. En la celebración festiva del día propio, prevalece la gratitud de los oferentes presentes, y el júbilo generalizado. Pero la celebración también resulta ser un pago. Las promesas han de cumplirse, pues (se dice que) si no, los infortunios recaerán sobre los incumplidores. No obstante, se trata de un cumplimiento muy peculiar. La similitud de la promesa con el contrato donaticio termina cuando se observa que no obliga a la "parte" sacra a proporcionar ninguna gracia; únicamente obliga a quien se arriesga con la promesa. La persona sagrada se concibe como libérrima en cuanto a escuchar o no las súplicas. Es más, el escenario de la ofrenda votiva es singular dentro de las posibilidades de dicho schema, pues el acto del cumplimiento expresa el reconocimiento en gratitud a la intervención de la deidad o del abogado sobrenatural ante la misma; pero comprendida como una gracia plenamente asociada a su arbitrio: desvinculada de cualquier atisbo de atadura obligatoria, por su parte, respecto a la formulación de la impetración.

Existe, con todo, un sentido añadido a la manifestación de júbilo festivo coparticipado en público, que fluye incluso más profundamente, vinculado al de agradecimiento y cierre del círculo promesa-cumplimiento. Más arriba señalé, siguiendo a Van Baal, que el don constituye una respuesta al fundamental problema humano de la incertidumbre sobre su ambigüedad existencial: del participar del universo, difiriendo, sin embargo, de él en tanto que sujeto. Pues bien, si toda comunicación -todo refrendo de la propia pertenencia a una totalidad- comienza por dar o por ofrecer, el acto religatorio que confiere el sentido de estar involucrado en una existencia significativa que proyecta al sujeto más allá de sí mismo, relativizando su alteridad y evitando así su aislamiento, consiste precisamente en esta ofrenda votiva, entendida como movimiento que culmina y cierra un schema interpretado como concreción de la gracia donaticia del "santo abogoso" (la curación, el término de un riesgo o una crisis vital) previamente suplicada por el oferente. Es la imputada intervención voluntaria de la instancia sobrenatural la que acredita la efectividad de esa comunicación existencialmente integradora, y a la vez personalizada en el suplicante. La ofrenda votiva no presenta exactamente las características del sacrificio, pues en éste la súplica y la inmolación de la víctima abren el lapso ritual, mientras que el ciclo de la primera es experimentado como demostración, ritualmente pautada y desplegada, de la religación: de la vuelta a participar íntegramente el sujeto en todas y cada una de las dimensiones del universo existencial, como cuerpo vivo recuperado y públicamente verificado (repito, con Rappaport,

3 Pues cambian los términos: de [dar-recibir-devolver], se pasa a [prometer suplicatoriamente-(recibir)-cumplir], siendo el segundo paso, ahora, interpretación del oferente. 
que la eficacia del ritual radica en su extensión a lo orgánico), como persona prójima en la communitas humana, y como humilde interlocutor escuchado desde la esfera sacra, pues experimenta en carne propia lo que constata como beneficio de esa divina audiencia.

\section{Bibliografía}

Bourdieu, Pierre (2012 [1977]) Bosquejo de una teoría de la práctica. Buenos Aires: Prometeo Libros.

Csordas, Thomas J. (1990) "Embodiment as a Paradigm for Anthropology". Ethos, 18.

Dow, James (1986) "Universal Aspects of Symbolic Healing: A Theoretical Synthesis". American Anthropologist, 88.

Douglas, Mary (1978) Símbolos naturales. Exploraciones en cosmología. Madrid: Alianza.

Ellen, R.F. (1977) “Anatomical classification and the semiotics of the body", en J. Blacking, ed. The Anthropology of the Body. London: Academic Press.

Glucklich, Ariel (1999) "Self and Sacrifice: A Phenomenological Psychology of Sacred Pain". The Harvard Theological Review, 92.

González, Sergio (2013) "Mito, experiencia y practica: relacionalidad y recursividad en el estudio antropológico del ritual" Revista de Antropología Experimental, 13.

Gudeman, Stephen (1976) "Saints, Symbols and Ceremonies" American Ethonologist, 3.

Jackson, Michael (1983a) "Knowledge of the Body". MAN, Journal of the Royal Anthropological Institute, 18: 327-45.

Kleinman, Arthur (1997) “"Everything that really matters': Social suffering, subjectivity, and the remaking of human experience in a disordering world. Harvard Theological Review 90.

Leach, Edmund (2006 [1954]). Sistemas políticos de Alta Birmania. Barcelona: Anagrama.

Lock, Margaret (1993) "Cultivating the Body: Anthropology and Epistemologies of Bodily Practice and Knowledge" Annual Review of Anthropology, 22: 133-155.

Mauss, Marcel (1991 [1934]) Sociología y Antropología. Madrid, Tecnos: 337-356.

Merleau-Ponty, Maurice (1962) Phenomenology of Perception. London: Routledge and Kegan Paul. Morinis, Alan (1985) "The Ritual Experience: Pain and the Transformation of Consciousness in Ordeals of Initiation". Ethos, 13.

Rappaport, Roy (2003) Ritual y religión. En la formación de la humanidad. Madrid: Akal.

Sahlins, Marshall (1988) Islas de historia. Barcelona: Gedisa.

Turner, Víctor (1980 [1969]) La selva de los símbolos. Aspectos del ritual ndembu. Madrid: Siglo XXI.

Turner, Víctor (1988) El proceso ritual. Estructura y antiestructura. Madrid: Taurus

Tylor, E. B. (1871) Primitive Culture. London, Murray.

Van Baal, J. (1976) “Offering, Sacrifice and Gift” Numen, 23: 161-178.

\section{$\cos$}

